\title{
ALGUNOS COMENTARIOS SOBRE LA EXCESIVA ONEROSIDAD DE LA PRESTACIÓN, CON ESPECIAL REFERENCIA A SU APLICACIÓN EN EL AMBITO DE LA CONTRATACIÓN PÚBLICA
}

\author{
Manco Antonio Ontroa Piana

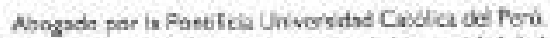

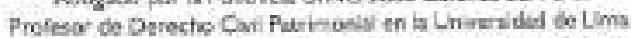 \\ Miartora del Corscio Corsutwo de ia Fonsca ADVOCATUS
}

"Lo que es verdod a la luz de la lämpora. no siempre es verdad a la luz dol sol"

J. Joutert

\section{Sumartos}

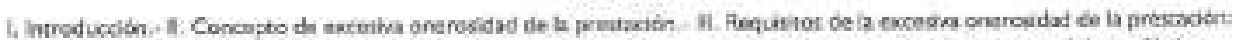

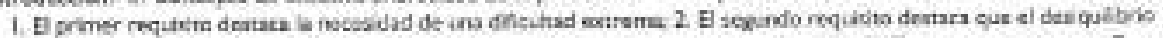

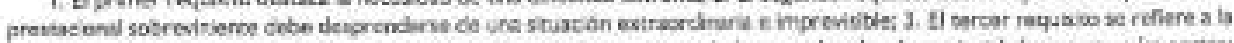

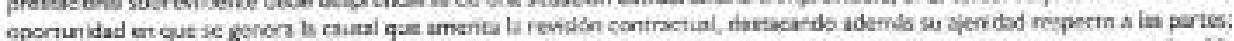

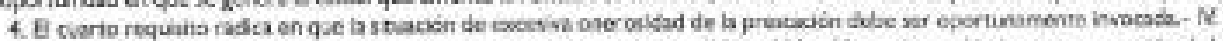

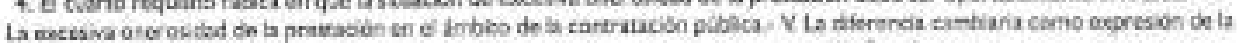

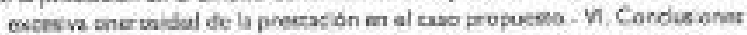

\section{INTRODUCCIÓN}

1. Ya temos tenido oportunidad de sostoner, en un trabajo precedente publicsdo gerercesamente por ADVOCATUS, que el contrato no es un fin ensi mismo sino un instrumento para el intercambio económico. El Ordenamierto furidico, con relación a dicha funcionalidad y sobre la base que existen intereses relevantes, dignos de tutela y procección, reconoce ol caracter vincuiante del contrato, lo cual reprosenta la mejor garantia que los términos del intercambio no seràn desconocidos unilacerá nì injustificadamente, pudiéndose compolor al cumplimiento de lo pactado o, de ser el caso, exigir ta correspondiente indemnización. En ese sertido, el contrato como instrumento negocial representa una autolimitación acordada por las partes, por cuanto son finalmante ellas las que, sobre la base de su libertad para contratar, acuerdan decerminado estatuto que regularź sus relaciones, adoptando las previsiones necesarias para asegurar sus respectivos intereses, en la medida que elio sea pasible - que resulte económicamente rentable o razonable.

Pero la celébración del contrato no significa que el acuerdo adoptado, y representado por las declaraciones de voluritad común, sea absolutamente inmutable; el Ordersarienco Juridico reconoce que pueden imwocarse pouteriomente situaciones excepsionaies, sesh originarias o no, considerando que el negocio colebrado habria nacido desequilibrado en cuanto al contenido de sus penstaciones, o que habria devenido en desequibrado. Esas situaciones van a derivar que, en palabra de un reconocido autor', se deba "volwor a ver" el contrato, esto es, se dabs revisar su concenido, abriendo paso a una declaración de heficaca a titulo de rescisión (si el problema existia al momento de contratar) o de resolución (si el problema se generó pesteriormence). Lo primero corresponde en nuestra medio a la lesión, io segundo a la excesiva onerosicad de la prestación. El común denominador es qut en ambos casos hay un desequilibno prestacional

Rersulta evidente que is sola referencia a la necosidac de inartener un equilibrio prestacional puede ripprisantar de por si un problemia, ya que se plantea conceptualmente la cuestión sobre

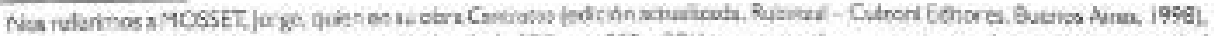

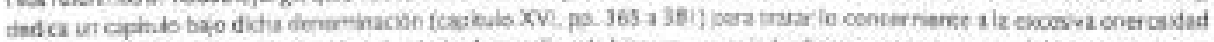

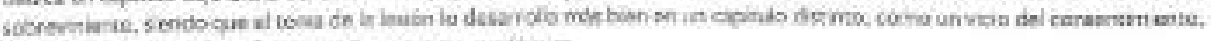

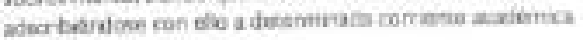


si el valor de las prestaciones es objecivo o subjetivo, y sobre si la dinámica negocial misma no presupane la axistencia - desde un inicio-de un desaquilibrio prestacional yz que la racionalidad del intercambio implica que uno contrata sobre la base que asigna mayor vakor a lo que adquiere respecto de lo que transfiere. Sobre este particulan por las razanas ya expresadas en un trabajo anterior? corsideramos que en materia de cantratación, el parámetro de reforeneja es el cel valor objecivo. en función a los valores del mercado, a lo que es comúnmente aceptado, siendo que el desequilibrio prestacional merece rechazo furidico cuardo se deriva, con ocasión do conoratar, de determinadas stuaciones abusivas ('ta lesión objetiva-subjetiva), y reclarra una reacción juridica cuando se genera de manera sobreviriente a la celebración dol contrato, quebrando el equilibrio originario definido por los propios interesados (excesiva cnerosidad de la prestación), afectanda de manora inesperada el normal cumplimiento del contrato.

No dobernos olvidar que desde una perspectiva sistérnica, el contrato no solo es in instrumonto que satisface intercses de las partes, sho que posee uma importancia mís trascendente porque el intarcambio benaficia finalmente a los diversas agentes económicos de la sociedad, quienes tienen ta pasibilidad de hacor uso de un instrumento seguro y sujero a ciertas rezies en las que prima, o debe primar, un elemental criterio de justicia y equidad, considerando que quienes contratar san personas cormunes, y no santos ni héroos, de manera que lo que se debe esperar, y se puede exigir. es un comportamiento razonable, diligenta, aceptable en función a las circunatancias, a ta mensura de riesges. En comecuencia, de gonerarse divergencias entre las contratantes, se trata finalmente de cquilibrar sis intereses concretos con los intereses abstractos de la sociedad. Ese es el gran reto de los órganos jurisdicciontles.

2. El presonte trabajo, ciła elaboración tiene como antecedente inmeciasto uma opinión brindada con ocasión del ejercicio profesional, y como antocedente mediato el intercambie de opiniones en clase ${ }^{3}$, no prenende desarrollar ure exúgesis sobre ta regulación de la excesiva onerusidas de la prestación en nuestro sistema logal, su propósito es mucho más simplo. El objetivo dol presente articulo es compartir algunas reflexiones sobro el tema en cuestión, considerando que por razones de tiempo y de metodologia muchas veces resulta manerialmente imposible agocar of estudio de una detarminada figura con ocasión de clase, ya que por lo general solo se pueden destacar los aspectos más relovantes. En ese sentido, se trata de un modesto aporte que ha kido estructurado sober la base de un caso real que en sinsesis corresponde a lo siguiente: una determinada entidad pública celebra un contrato de obra en moneda extranjera con una empresa conoratista, sienda que en etapa de liquidación se plantea un requuste prestacional en los pagos que debe realizar la entidad a favor de la tontratista, reajuste derivado de la diferencia cambiaria generada entro la fecta de celebración del contrato y las foches de pogo do les valorizaciones. La contratista se sustenta en la figura dn la excesiva cnerosidsd de la prastación, por lo que su solicinud de reajuste se legitima en la necesidad de mantener el equilibrio prestacional origharios, por su parte, is entidad, rechaza et. reajuste considerando que dicha posibilidad estí doscartada dosde el momento en que se contrató en monedle extranjera y no on moneda nacional, lo eual presupone la avunción implicita del riesgo cambiario, siendo ademźs que el contrato establece que no hay posibilihad de reajuste alguno del precio. Resulta eviderce que, más allá dal caso expuesto. lo impertante es analizar los requisitos de aplicación de la denominada excesiva cnerasidad do la prestación, así como determinar si dicha figura es o no ajerna a la contratación pública.

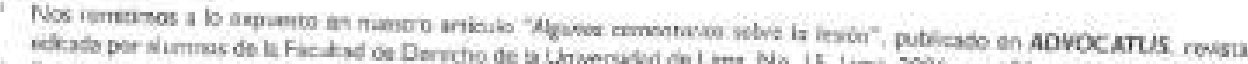

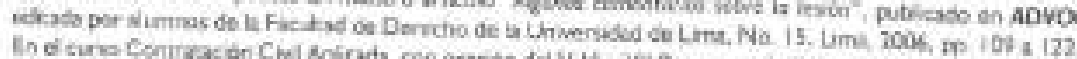

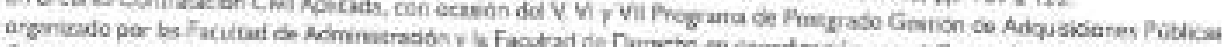

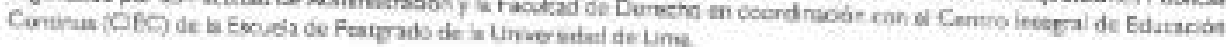


En razón de loenunciado, desearnos plantear el tema de la excesiva onerosictud de la prestación no solo en el ámbito de la cantratación priveda sino ademis extender nuestros comentarios a la contrataciòn pública. Y si bien somos cancientes de nuestras limitaciones respecto al ampla espectro de materias que comprende el Derecho Administrativo, pretendemos (torverariamerae) de afgura manera contribuir al estudio de ternas puntuaies on materia de contratación pública, ya que a lo largo de los dtimos anos hemas corrotatado la insuficiencia de ostudios y ensyyos sobre el partic:dar. sunque tambiön un creciente interes en el Dorocho Admiriscrativo, como se aprecia particularmurta en nuestra Facultad de Dereche con la creación de un circulo de ostudios a iniciativa de los prepies alumnos. Conforme se ha manifestado en mis de una oportunidad, en nuestra medio al Estado es el gran contratante, el gran adquirente de bienes y servicios, de zli que los proveedores de estos úlimos se interesan en pragresiva mayor medida por las normas sobre contrataciones y atquisiciones del Estado, y en particular sobre el régumen icgal aplicable con ocasión de la ejecucibn contractual, ks que les permite seguramente estimar ventajas y desventajas. Se requiere, en consecuencla, de une mayor contrabución de quieres estarros relacionados de una u otra forma a la contratáción píblica, aunque estamos seguras que en t carrino se padran ir paulatinsmente ajustando cencaptos, ideas y propuestas.

\section{CONCEPTO DE EXCESIVA ONEROSIDAD DE LA PRESTACIÓN}

1. Là excesiva onerosidad do la prostación comaspendo a una figura que puede ser imocada tuando, de manera sobreviriente a la colabración de un contrato, se presentan situaciones de car ácber impenvisible y extraondinano. que justifican la necesidad de replantear los términos y condiciones acordiados inicla mente fincrementanda of valor de la contraprestacion o reduciando ef de la prestación afectada\} para fines de restatiecer el equilibrio negocial perdido o afectado como corsecuencia de los indxados everto5, sendo que solo de manera excepcional es posible resolver el contrato, ya que nuestro ordenamiento legal primilegit la denominada "preservación del contrato"

La figura an cuestion es un remedio legal frante a situaciones que pudiesen representar uns maniflesta e inequivoca injusticia o inequidad en el intercambio, significando que se dejará de aplicar la rigurcsidad dol cardcter virculante de las declarsoiones contractuales flo deciarado es lo querido, sierdo que bo declarado tierse caracter obligatorio, saivo que se demuestre que lo declarado no era lo efectivamento querido) para dar paso a la pesibilidad de modificaciön sobre la base que se han presentado situaciones ajenas a las partes que legitimian una ravisiôn del consenido prestacional del contrato. En efecto, siendo tedo contrato un vínculo oblebacional pars fines del trifico, el mismo deberia ojecutiese estrictamente conforme a lo daclarado voluntariamente por las partes intervinientes'; sin embirgo, dicha rigurosidad formal, que correspence a un paradizma del dorecho contractual (ta "obligatoriectad" del contzato), se ve afectada cuande se presencan circinstanciss que corresponden a la imprevisión. ya gan se enviende que las partes se sometiercon a un determinado regamento sober la baser do lo que era razonablemente previsible, no de aquello que no pudieror ni podlan escimar, por ló que en este ưtmo caso, se explica plantear una revisión o modificación del contrato [y solo excepcionalrente su resolución)?

Más que un simple veine de imprevinion, tay decris una real aheraciön de las direirstarcias bajo tas cuales les partes contratanon en au apertunidad, derivando decha aiteraxión en la afoctación actual que padece uria de elias, de manera que a haber variado as circunstancias, caraceria de semtido mantener la irmucablidad del acuerdo cantractual, Eso os lo que justfica, en primera instancea, ia rensićn dol contenido peestational. sea de comùn acuerdo o sea por la hutoridad juristiccional

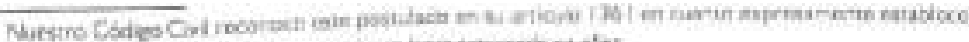

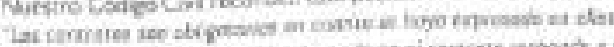

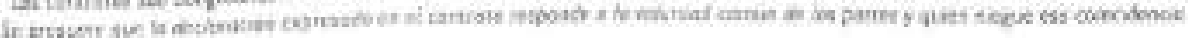
ititar antmily
} 
competente a selicitud do parte interesada y, en último caso, cue pueda optarse por in resolueiort del contrato.

Debe destacarse que, al menos desde el punto de vista tebrico, se asume que como consecuencia de la contratióón ambas partes cobtiener beneficios, estabieciajndose lo que ellas estirran sobsranamente como el propio equilbrio de sus intereses. Resulariás sumstrente cuestionable que se obligue a cumplir el cerrerate (que no es sins un instrumento) eerferme a lo pactado en su oportunidod, st de manara posterior se presentan stusciones que quisbran el equilibrio definido an su mornento por los propios intefesadas, yz que por causas a a anas a las partes una de ollas estaria obteriendo una mayor vencaja en exacta correspondencia y consecuencia de in desventaja que estaria padeciendo la contraparte, la misma que estaria en una shuación de extrema dificultad para honrar lo que inicidmente era absolisamentu posible de ejecutar. En otras palabras, si las partes estructuraron al contrato sobre clartas premisas, el mismo debe estar adocuado a las mismas de maners permanente, porque de lo contrano el instrurrento se comvertiria en un fin, desnaturalizalndose.

2. La tixperiencia demunstra, $y$ asi ha sido reconocido jurisprudencial y lezislativamente, que lusgo de celebrado un conerato (ol cual debe presentar ciectas características que indicarnmos más adelante, ya que no es lo mismo un contrato de ejecución instantánea, que uno de ejocución diferida o scsterida er el tiampo) pueden prosontarse en su atapa de ejecucián ciertas circunstancias, ajenas a as partes, que determinen la ruptura del equilibrio prestacional (exprasa o sicitarnente reconocido). de mancra qie el cumplmiento del contrato conforme a los tóminos y condiciones irricialmence previstos o programados (aplicando rigurosa o liseralmente ol principio de "obligatoriadad" contrscrial\} afectaria a un elemencal criterio de justicia, ya que se estar '́a imponiendo un cumplimbento sebre la base de lo enunciado textualmente an at contrato artes que sabre la base de la efectiva y real posbilidad de las partes, vialentaindose la obsarvaneia de un prineipio general como la es el de la buena fe, rector en materia de contratación. Para evitar procisamente esas situaciones, se recenoce que el afectado por un evento extraordirario e imprevistbie que afecto grave, severamente, el eumplimierto a sa cargo, tomándolo en notablemente más oreroso por altoración de las circunstancias baja las cuales se contrató, puede legitmarvente plantear una revisión del contrato para que se determine la mejor manera de restablocer el equilibrio perdido o, or su defecto, dads que se habria afectado su interés negocial muisno, para que se proceda a la resolucí́n del contrato (sujpto a ciertos condicionamientos legales).

Por ta tanto, si hien lo declarado (etepa de celobración contractual) es lo querido $y$ debe eumplirse obligatorianente, ello esta sujeto a que respoctivas condiciones (etapa de ojecución) se mantengin esencialmente, ya que de prosentarse situacioncs cloctivo, reaimante, extracritinarias e imprevistoles que dificulten el cumpirriento, haciéndolo mis oneroso, más gravose, casi heroico, el interesado puede requerir ura revisión jurisdiceional del contrato, siendo excepcienal la pos atilidiad

3. Nusara Código Civè regula expresarnente la figua do la encesiva oner osidad de la prestación por akeracián de las circunstancias on sus artícuios 1490 a $1466, y$ más alli de las criticas que nos pueda merecer dikha regudación, lo cual no es maneria del presente trabajo, nos interesa destacar el rógienen ul cual se suieta la figura, conterido en wi articulo 1440, conforme a lo siguiente:

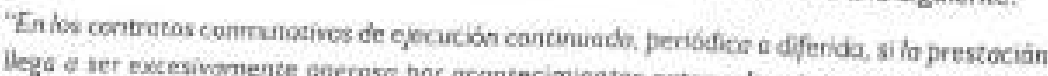

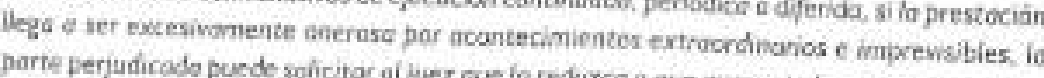

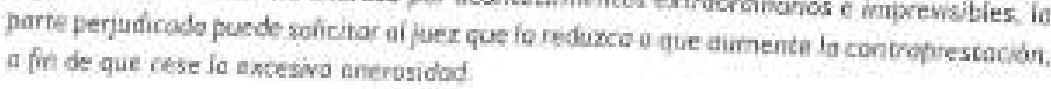


Si efis na fuers posible por fo notundeza de la prestoción, por Jas curcunstoncias a si lo

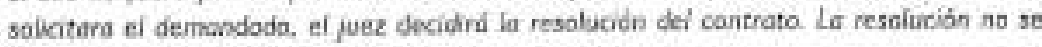
extiende o las prestocianes cjecutoules".

Del enunciado legal precedento podemos referirnos a ciertos aspectos puntuales:

a) En primer lugar, la figura en cuestión no soio se aplica a fas contuatos de duración. sino tambión tratbindose de las coerratos cormutativas de fjecución inmediata-cuando la prestación afectada fue diferida sin culpa del deudor-, a los contratos áeatories-cuando la afectación sale del riespo normal o propio dal respectivo contrato-, y a los contratos de prestición unizateral (conforme a los articidos 1441 y 1442 del Código Colli, respectivamente)

La clasificación contractual de conoranos conmutativos se asionta en que, al momento do su celebración, las partes puoden estimar, costear, las ventajass y dewvertajas que se deriver del vinculo, esto es, comparar ciertamente beneficios y sacrificios; a diferancia de los contratos aleatories, en donde las wentajas y desvencajas depender de la suerte o azar, de manera que no se puaden asegurar beneficios ni sacrificios. La regla general es que el contrato afectado sea uno conmutativo, porque de modificarse las circunstancias que en su momento fueron consideradas para estimar ventajas y desvervajas, y sobre la base de la cuales se tomó la decisión de contratac, resula admisble que el alectado quede legitimado para replantear los términos y condicianes contractuales:

De otro lado, los contratos do ejecucib́n inmediata son aquellas que no roqueren o no se ha previsto plazo alguno para su ejecución: dichs clasificaciōn se opone a la de ios contratos de cursción o de ejecución sestenida en el tiempo, que incorporan -por su naturaleza o por pacto-el elemento dal plazo, ta temporalidad -determinada o indeterminaka-pudiendo ser Ia ejacución prestacional continuada (ininterrumpida) o periódica (con intervalos). Tratándose de un contrato de ejecución inmed ista, que impica que el vinculo se extingue inmediatamente a la celebración, resulta marifiesto que no hay un insenvilo de tempo para la ejecución prestacional gue justifique la aplicación de is figura de la excesiva oneratidsd de la prestación. sávo qus dicha sjecución prescacional no se hubiese podido ejecutar de manera inmediata por cassa ajena al deudar, como sera el caso en que el acreedor no asuma opertunamerite su carga de colaboración y hubiese sido constituido en mora por dicha razón.

Poe Gitimo, los contratos pueden ser de pressacison pluritateral o unilateral; en los primeros. cada parte asume obligociones a faver de la contraparte mis alli de la eporounidad de su sjecución (instantánea o no, periódica o diferida), mientras que los contratos unilaterales envrafian que solo una parte asume obligaciones, por lo que la prestación a su cargo no pesee ni puedu reclarnar contraprestación alguna. La situsción tipica es que el contrato afectado por cambia de las cincunstancias ses une plurilareral ya que sólo asi puede plantearse el terns del incremento de la contraprestación: no obstante, plede oratarse tambièn da un contrate unlatern, por la que del universo de solukioces legalmente previstas solo podrá aplicarse la reducción de la prestación afectada (si lo permite su cbjeto, en el semido si es divisblo o no) o la resolución contrartual.

b) Orro aspecto que merece destacarse y que se desprende de los alcances da la norma lega anteriormence rearoducida, of que estamos fronta a uma figura que representa un beneficic legali: la posibilided de reciamar un reajuste prestacional, más alls que el contrato no coneenga previsión algura sobre la materia', sendo que st invocacián por ol interesado debe ser

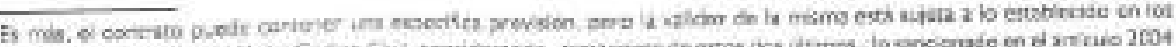

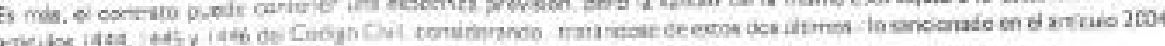

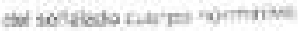


oportura, por cuarto la que se astá generando es ur espacio para la revisión dé coctuervido contractual, lo cual es certamente una situación atipica, ya qua nucstro sistoma lepal se asienta sobre la bese del carticter vincularite de lo convenido en su oporturidad mediante la declaración de voluntod comǘn.

En cesc ordan de ideas, se requiene de espocial cuidado para fines te calfikar si una determinada situación cumpln o no con las exigenclas logaios do peseer un carácter extraordinario a impcevisible; entendernos y postu amos que el rospective criteno debeser restrictivo porque la regla general en materia contrzecual es el cardcter obilgatorio de lo pactado, siendo que las partes en la medida de lo razonable han debido calcular y valorizar les riesgos a los cuales estaria sujeto al negocio que están celebrando." No debe olvidarse que cualquer solución jurisdiccional que se propoccone debe considerar que todo eantrato cumple una dobla funcionalidad, en términos diadicos. es un mecanismo de intercambio entre dos partes contratantes, empero, en términos sistérnicos, hay detrís un interús de la sociedad, siondo que los agentes económicos tomaran decsiones de negocios sobre la base del valor que se asigra a un contrato en nuestro medio, de alli quela posibilidad de intorvencid́n de un tercero para rescablecer el equilibrio perdico, o para defar sin efecto al cortrato fa pesar que su curriplimiento es teóricamente posible, con dificultad, pero posible) debe ser ciertamente ia regla de excepción.

Siendo un berneficio legal de ejercicio discrecional por el interessdo, su invocación no enerva of derecho de la contraparte de demandar el eumplimiento del contrato conforme a lo acordado en su oportunidad, ya que la exigibilidad del insremento de ia contrapresiación, - la posibilidad de poder oponer la reducción de la prastación alectacla, están sujetos a una declaración corst tutiva de carácter jurisdiccional, con mayor fazón al extremo resolutorio. Tendría que lacerse uso de determinabos mecanismos procesales para suspender al menos la preternion de la contraparte.

c) En tercer lugar, también debernos destscar que estamos ante la posibilitiad excopcional de resalucián contractual a la cual no son de aplicasión los procedimientos extrajuriśdiccicnales previstos en les artícules 1429 y 1430 del Código Civil, las cuales se refieren a una situación de incurplimierto grave'. Se tata de la posibilidad de una resolución contracsut que no opera por si misma, por al solo máriro objetivo del supuesto de hecho previsto en la respectiva norma. sino que demanda de invocación por la parte interesada, poe lo que sobre dicha base las parțes puederial canzar directarente un acuendo (que correspondera a lo que nuestro Código Civil denamina muaus disenso) o recurrir a la instancia jurisdiccional cortespondiente para que resueva lo que representa definitivamente un problema, controversia o desencuentro en etapa de ejucución contractual, de manera qua la resolución en cucseón-deser imocada de manera unilateral-requerira necceriamence de un pronunciamiento constitutivo jurisdiccional.

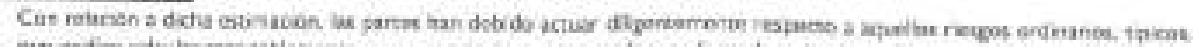

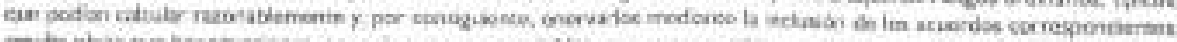

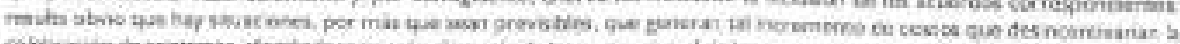

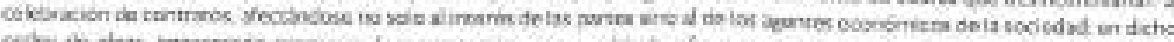

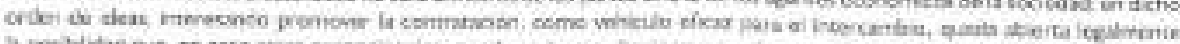

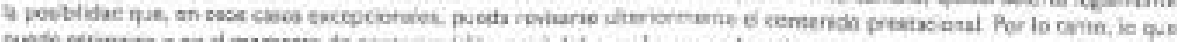

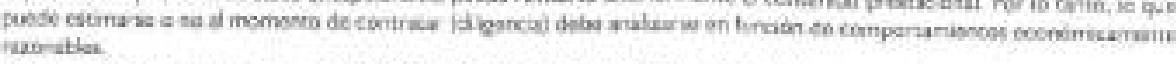

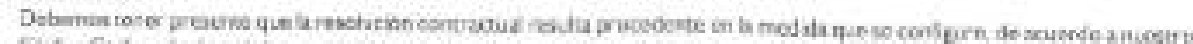

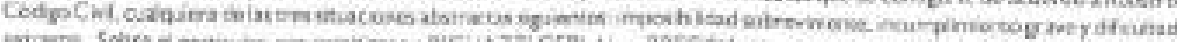

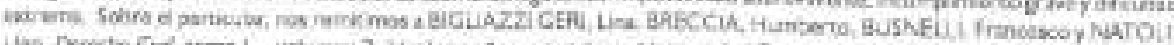

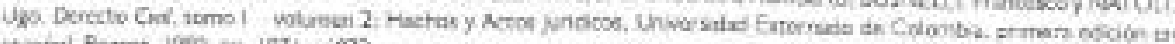

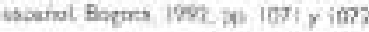


Y an lo que se refiere a los efectos de dicha resoluciōn, las mismos dependerán en euanto su eflcacla ex tunc o ex nunc de la naturaleca del respectivo contrato, esto es, scgún se trate de un acuerdo de presración ủnica o no, de manera que la parte final del articulo 1440 del Código Civil ("Lo resolucilan no se extiende a los prestacianes ejecutodos") salo puede entenderse referida al caso de "unidad de vinculo, pluralifad de prestaciones", donde hay una divisibiidad prestacional, no $\mathrm{a}$ caso de "unidad de vinculo, unidad de prestación". Se advierte que si bien la parte final del señalado articulo 1440 es concortarte con lo sancionado en el articulo 1372 del Código Civil, en cuanto a los efectes de la resolución, en ambos casos se parte de un mismo presupuasto: contratos de tracto sucesivo.

\section{REQUISITOS DE LA EXCESIVA ONEROSIDAD DE LA PRESTACIÓN}

Podemos considerar como requisites o presupuestos constitutivos de la exceeiva onerosidad de la prestación a les siguiantes:

- Dificultad extrama, manifiestamente onerosa para la ejecuxién normal de la prestación comprometida.

- Que dicha dificultad extrema provenga de Lna situación extraordinaria e imprevisible.

- Quela indicata situackon extracordinaria a imprevisble sea sobreviniente a la celebración del contrato y ajora a las partes.

- Que la dificuktad extrema sea operturamente invocada por el interesado.

Solorer la medida que se cumpla cancimentemente con los indicasles requisitos, quien irmoque la figura de la excesiva onerosidad pedrá lagirimamense solicitar la reducción de la prestación a su eargo o el incrcmento de la contraprestación (y solo de manora excepocional, de no ser posible por la raturaleza de la prestación, la resolución), lo cual a su vez presipone que d contrato se encuentra en proceso de ejecución, siendo que la contraparte-urze vez que es emplazada-pucde cptar no solo por la reducción o incremento sefialados (contradiciéndolos) sino inclusive directamense por la rosolución misma, esto es, que se deje sin electo al contrato celobrado por cuarto habria perdido incerés an el mismo, de manera que no se justifica que pueda proseguarse con su ejecución bajo condiciones distintas a las inicialmente previstas, este derecho potestativo se fundamenta en que la causa que justifica invocar la reveión del contrato no solo es ajena al perjudicado sino también a la contraparte, csto es, no hay culpa de las partes respecto al thecho ayeno extrocrdirscio e imprevisible.

\section{El primer requisito destaca la necesidad de una dificultad extrema}

La d ficultad excepcicnal o extrema no puede confundirse con la imposiblidad porque de lo contrario la solución juricica no seria un reajuste prestacional (o, excepcionalmente, una resolución contractual juriscicsionalmente declarsda) sino la reselución de pieno derecho, ipsa jure, por imposibilidad sobreviniente.

a difieulead extrots entraía que la prestación afectada ns posible de cjocutar pero en un contexto sustancial o completamente distinto al inicialmanre previsro. lo cual deriva que la parte interesads se vea gravemante afectadh en sus expectativas negociales, dado que el equilibrio contractual acordado or iginariamente (on los vèrminos en que se habria corvenido, sea implicita o explicitamente) se tabría quebrado y, no obstante ello, se le exige que cumpla con lo declarado, a pesar qua la base del negocio mismo ha camblado radicalmente. Si dicha parte afoctada tuviess que contratar en las condiciones actuales, no se generaria probablemente acuerdo alguno 0 , al menos. resulta razonable presumir que plantearia condiciones distintas en la respectiva negocisción. Por ello, sobre a base de la buena fe fpribicipio rector en materia de contratación, de conformidad con 
el articulo 1362 del Código Civilh), de esperar y exigir comporvamientos razorables, se estima qué la parte perjudicata por la dificultad excepeianal e extroma puede feclamar jurisdicconalmente -al presentarse el evente justificativo durante la vigencia del contrato-una revisión de les tórminos del intercambio para que los mismes sean finalmente justos, restabieciéndose el equilbrio fecanocido por los propies actores al momento de contratar, esto as, la famosa ecuación exonómico-financiera. del centrato afecrado,

A mayor abundamiento, de no enconcramcs ante tha dificultad excepcional o extrema, que conforme analzaremos a continuación debe desprenderse de un acontocimiento extraerdinario e imprevisible, estaremos ante uma dificultad habinual, comín, ordinaria o propia del fiesgo o devenir temporal de todo contrato, lo cual corresponde a una situación que no justifica juridicamente una revisión (ya que las partes pudieron raromablemente anticiparse $y$ adoptar las previsiones necesarias para resguaruar sus propios intereses) y cons guiente mocifcación dol contrato celebrado, menteniéndose rigurosamente el carácter vinculerte de lo pactado en su opartunidad, por lo que manos ain se justifica la posibilidad de una resolución contractual.

A afoctar ta dificultad extroma a is prestación, ello dencta que nos encontramos ante un contrato en proceso de ejecución de manera que la excesiva onerosidad solo es posible de invecar mientras aquel no se haya extinguido, dado que la posibilidad do obcener un reäuste prestacional us lo que permitirá cumplir satisfactoramente a quien se sienta afectado por la dilicultad extrema, presiguëendose con la ejecución normal del contrsto celobrado.

Si las prestaciones ya han sido ejocutadas, y d vihcibo cblyarienal ha quedada extirguido, no se justilica revisisn alguna, porque el devidor pretendidamente afectado ya cumplis, esto es, de su propia conducta se desprende inequivocamente que pocia cumplir, de manera que no existia realmente uns circunstancis extrema de caracter extraordinario e irgrevisible, sino mis bien lo que se padria calficar come un riesgo tipico, normal u ordinario. E inchusive si el contrato hubiese terminado por vencimsiente de su plaze de vigencia (se hayz ejecutado o no), consideramos que tampoco resujkaria valido invocar la excesiva onerosidad por cuanto yz no hay relación contractual vigerte.

Nuestro Códga Civil implichamente reconoce estz exigncia desde el mamento en que establece que las soluciones consisten en un reajuste de las prestaciones o en la resolución contractual. lo cual presupone que el contrate está vigente y resulta, literalmente, plenamente exigible, de alli la reacción de quien se sienta perjudicado por la sinzación extracrdinaria e imprevisiblo.

\section{Elsceundo requisito destacia que al descquilibrio prestasional sobraviniente debe desparenderse de una situación extraerdinaria e imprevisibla}

No exbste una definición legslativa sobre lo que debe entenderse por extraondinario e imprevisible para fines de la excesiva onerosidad de la prestación, por lo que la respectiva cal ficación as finalmente juriscicciond, atendiendo a las circumstancias, lo cual represenca una fórmula flexble quo nos parece apropiada pero qua presupone el entendimiento jurisdicconal que se estál ante una figura de excepóon, respecto de b cual se debe combinar ura visión disdica y sistétrica de la contratación, No obstante lo anterior, podemes tomar como referencia la menoión contenida en ef articulo 1315 del Codigo Civil en cuarto califica al caso fortuito o fuerza mayor como emente extrzordinario, impresisble e ieresistible.

Con relación alas caracteriszicas da las causas no imputables a las partes (caso fortuato o fuerza mayorl, consideramos que la shuación que justifica ta revisión contactud por excesiva onercaidad

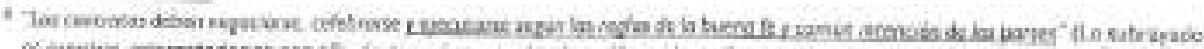

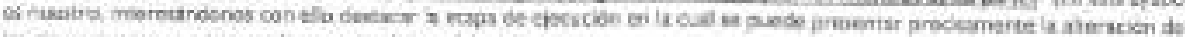

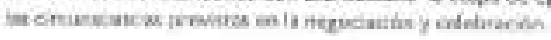


Le la prestación no pueda ser irresistible porque de ser asi estariames prácticamente en el ámbito de la imposibilidad sobceviniente, provisional o definitiva. lo cual genera una suspensión $\phi_{\text {, de ser }}$ el caso, una resclución ipas uure. De manera acicional, debe tenerse presente que la situsción de excesiva onerosidad faculta a invocur la revisión contractual, lo cual presupone que siempre es factibie el cumplimiento, asin en soveras condiciones. La posibilidad de revisión cvidencia que el contrato erdi viganto, pandiente de cumplimiento parcial o total, conforme hemos destacado procodenternente

¿Qué se cntiende por extraordinario? Es lo que se aparta de lo común u ordinario, lo cual en palabras de OSTERLING y CASTILLO significa qua "Se troto de ofgo que se encuentra dentro del campo de la exceppional, de un ocantecimiento que se produce par excepcióa, lejas de lo que en farma narmal o notund se esperc que ocurra. Lo extraurdinario es, pues, lo que atemea a immpe en el corso natural y normal de los acantecimientas, quebróndalas. frvodie temporaimente el espacio de la comán, de lo ardinaria. Vemos que este concepto vo seriamente Igado a io imprediceblulod a imprevisiblidad" "(Lo resalado es muestro).

Por su parte, ¿Quí se entiende por imprevisible? 'El hecha a evento es imprevisiale cuando supera o encede la aptitud nomal de previsión del decudor de le reloción cbìgatoria. En otras palabras, el deudar tiene el deber de prever lo normalmente previsibie, la que equivale a decir que el ocreedor puede exigir un nivel mínims de previsión. ( . ). Este punto es bastante delicodo, yo que es fócil entrar en el campo de las subjetividadec. (...). Vemas que lo imprevisibilitad comine al lodo de los deberes de ditgencia, pridencia. cuidadin. Esto quitere decir que el evento no solo debe revestir la objetividad en si mismo como hecho extraordinario, lo cual se demuestra sin moyores problemas al analixar Ia frecuencia o habitualidod del suceso, sino que ademés se requiere del elemento inherente af individuo, relativo a fo conducta diligente que se espera de ell. Esa canducte puede referirse o un pocràn standard abjetino del hambre medio (...) o ser de carte subjertiva, camo evaivor les posibilidades de previsiotn del deudor en coda coso especifico, es decic etendiendo a fas condicianes persanaies del ogente $=10$ (Lo resaltado es nuestro).

Estos dos requisitos son básicos para poder entender los aleances da la figara, ya que están en pugna dos grandes peincipios civiles resumidos en las expresiones latinas Pacta sunt servenda $y$ Rebus sic stontibus. De un lado, ta seguridad juridica enfarizada en que estamos sujectos a lo dedarado. zumiendose que es lo querido (articulo $|36|$ del Código C.Vil), y ello tiene cardcter estrictamente obligarorio (en las términos convenidos al momenno de contratar), por lo que lo pactado debe cumplirse porque esa ha sido la voluntad común. Y, de otro tado, el principio de baena fo y común inconción de las partos (articulo 1362 del Código Civil), lo cual no se agota en la negociación y celebración, sino que se extende a todo el proceso de ejecución contractual, afirndindose la necesidad de un irsercambio justo como sustento de la seguridad juridica, to cuà presupone raspetar le ecuación económico-financiera del contrato.

Por ello, ha lectura del evento que puede ser conopocicado como extraordinario e imprevisible deba ser rigurose excepsiaral, porque de lo contranio podria estar afectindose el caricter vinculante de tedo contrato. promoviéndose el incumplimicnto, a imposición de términos distintes a los queridos o frustrándose el ircerés de las pertes, todo lo cual puede derivar en que se tormine decalentando la contranación, instrumento esencial para el intercambio de bienes y senvios en beneficio de ta sociectad toda y que por elo trasciende del interés individual.

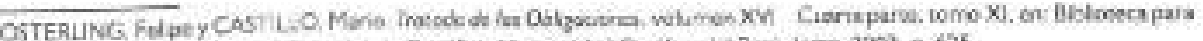

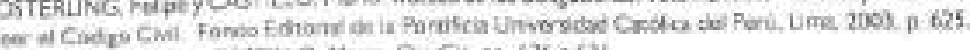

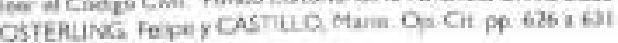


Si admitimos qua un contrato es un vinculo obligacional que permite satisfacer inmediatamente los intereses de las partes contratantes y de manera mediats. los de la sociedad en general, resulta obvio que la calificación jurisdiccional de lo que es extraordinario o imprevisible debe sustentarso en lo que razonablemente se podia estimar o no al momento de contratar, considerando la propia experiencia de las partes y sus respectivas posibilidades de asurmir eficientemente o no los respectivos costos de previsión", por lo que se debe cuidar de sopesar si los cambios en las condiciones contractuales son de tal magritud que gerenan ciectivemente una dificultad extrema en el cumplimiento, convirtiéndolo a éste casi en uj acto heroico, respecto dol cual dol Derocho no puede permanecer ajeno y de alli el "wolver a ver", o si se traza simpleminte de una situación en que el afectado debe asurmir las consecuencias de sus omisiones con ocasión de negociar y celebraf el respectivo contrato.

En palabras de MESSINEO: "Se requiere, pues, el concurso del canbicter excraoviniario $y$ de fa imprevisibilidod. For to tanto, es irelevante no solomente la anerasidad excestva determinado por un

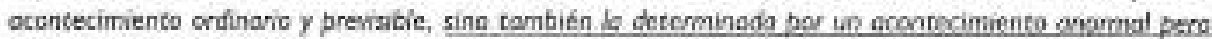
prensible. Y eso tasto más sr en el momento de ia casclusión del cantrcto se habion perfilado ciranstancias que, con certezo o con extrema probabilidad hubiesen candueldo o le eftercación de lo situcción económica tomodo en consideroción por las portes" I2 (Lo stbrayade es nuestro). En ctres pabbras, habrá una reascićn juridica por alteración de las circunstanoias en la medida que la actiación de les centratantes no hublese justilicado establecer raxorablemente un mecarismo contractual para enervar las circunstancias extracordinarias 8 impeevisibles, por más que estas ulitimas se hutbiesen "perfilado" al momento de contracar; empero, si las pertes pudieron tomar razonablemente las provisiones del caso, especificarnente la parte actualmene afectad por la excosiva onerosidad de la prestación, ello cocresponderá a una asunción voluntaria de rlesgo, no trasladable par cierto, yz que en su momenco se tumo la posibilidad real y ciera de adoptar las medidas más converientes para noutralizar la contirgencia:

Suguendo el raxonasiento expuesto, resulta valido introducir la distinción conceptual antre riesgos típítos (que se pueden califlcar como erdinarios o nomales, denominândoseles tambiön riesgos empresariales) y aripicos (coctravedirarios o anormales). Oto tema verí determinar, sobre La base de la raronabilidad, al examinar la eficiencia en la toma de decisiones durante tas ctapas de negociación y de celebraciog de un cocitrato, cuándo escamos arte una situación efectivarmente extrzordinaria e imprevisible, e en palabras de MESSINEO, si el efecto en cuestión por más anormai (extraordinario) que sea resulta siendo absolutamente previsible.

\section{El tercer requisite se refiere a h oportunidad en que se genera la causal que amerita la revisión contractival, destacionde además su ajenidad respecto a las partes}

E desequilibro prestacional debe ser sobreviniente: Este tema se asocia estrechamerve con la asiguación del vajor prestacional y al paradigna chi en materia contractual sobre equlibrio prestacional.

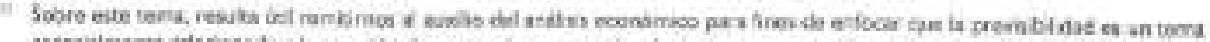

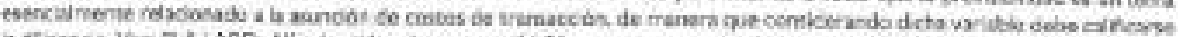

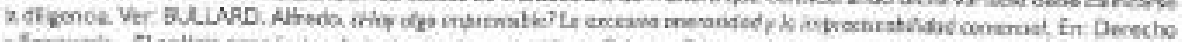

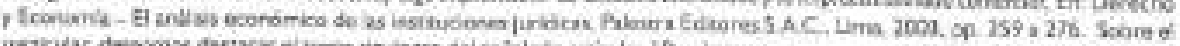

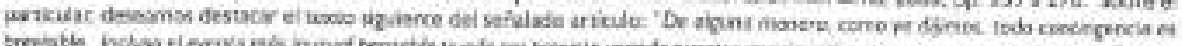

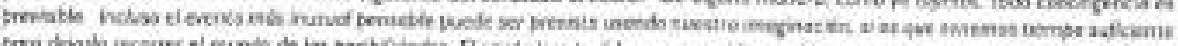

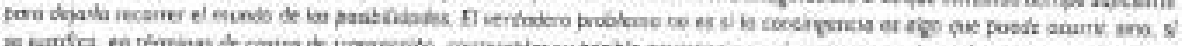

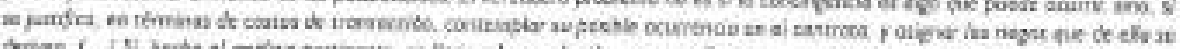

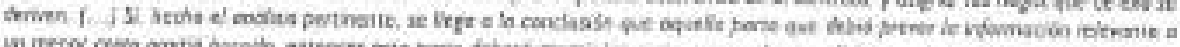

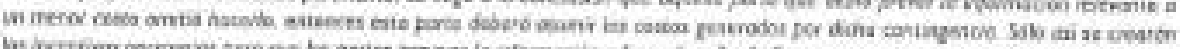

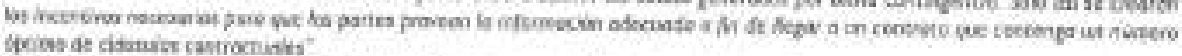

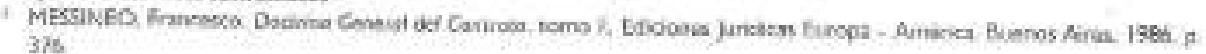


Son ciertamente las partes fas larradas a fijar el vaiar de las prestaciones en el contexto de una negociacichn paritaria, en función a sus propios intereses; en ese sentide, al concepto da equlibrio prestacional carece de un afectivo sustento por euanto no havy valores objecivos; les bienes y senvicios no valer por si mismos sino en función a los egentes econdmicos, as sus necesidades, a la oportunidad de hacer negocios, al costa que entrie una ejecución contractus en el riemps. 12 Desde esa perspectiva son las partes las que iderifican su propio equilbrio económico-finarcieco. valorizando las prestaciones segúnsus proplos intereses, lo cua conduce a su decisión libre y soborana de contratar, esto es, de generar un vínculo juríbico que será de estricto curnplimiento atendiendo a que "lo declarado es lo querido".

El problama se genera cuando, luego de celebrado el contrato, con la posibilidad de poder acordar cportuma y tazonablemente las previsiones del caso, se genera una situación excraordinaria e imprevisble que afecta el cumplimierto del contrato, tomando en mas onerosa la prestación a cargo de uno de los contratantes. No se tratn que la contraparte obtergz mayores beneficios a las iniciaimente previstes, sine que sag mayores baneficios se despenden directamente de un mayor sacrificio que te astaria exigiendo, de monera sobreviniente, a la parte afectata, la cial sigrifica quebrar cl equilitario prestzcional defindo por las propias partes.

En ese orden de ideas, asi como of desequilibrio prestacional originario puede derivar en la portinencia de invocar la "lesión (en la rectide que se cumplan los requisitos no sólo objetivas sino fundamentalmente subjechos previstos en nuest a legislaciśn civilh, si al desequilibrio es sobrevinionto a la ceicbración del cortrato, esto as, se produce en la etapa de ejecuckón, se genera, en la medicla cae so cumplan con los requisitos comespondientes, la pesibilidad de imrocar la excesiva onerosidad De la prestación para evitay que esa ejecución contractual sea abusiva, concraria a la buena fe, impidiendose finalmente un enriquecimiento indebido.

Sin perivicio de lo precedensemente cnunclado, la difficultas peratstondi debe derivarse de una situación ajena al control de las partes (téngase presente que nadle debe irmocar el hecho propio a su favor, seu parz derrendar un reajuste prestacional o para optar por la resolición), por lo que de mediar culpa el tema se soluciona conforme al rógimen legal sobre inejecución oblipaconal.

Asj como tratind ose de la imposibilidad sobreviviente de la prestación por causa ajera a las partes existen dos soluciones juridicas concoptualmente posibles, pero opuestas entre s: Pericuturn est debitariy

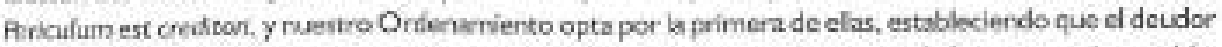
de ia prestación qua se ha tornadio en imposible asuma el respectivo cesto de la causa no impunble: perdiendo al derecho a la contraprestación ( $(s)$ la hubiera), lo cus en palabras de ZUSMAN sigrifica optar" por la solución menos injusta para las partes en conjunto (mal monor)", de la misma manerz se presenta ina disyuntiva en nuestro Orderamienco cuando estamos ante una difitulad extrema por causa no impucable a las partes, ye que conkorme hemos manifestado correspondera optar entre los prinxipios Picto sume servondo y Rubus sie sacricibas, wiendo que la aplicacoón de esta Citimo serí pos bie de manera excepcional s y solo s'se demuestra tanto la ocurrencia de un evento extraordinario e imprevisìle, corno que dal irvismo se denva la generación de ana excesiva onerosidad en la ejecución de la prostación alectad. Podri cuestionarse si se afecta o no la seguriobad juridica, pero no es mencs cierto que se trasa de una solución en la que se opta deodidanente por la buera fe obijeriva o probictad, reforzindosa la

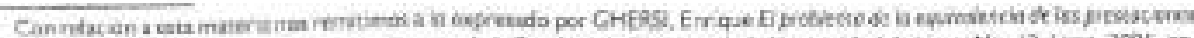

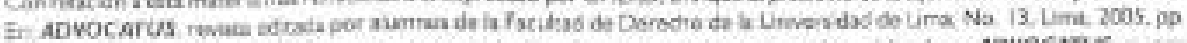

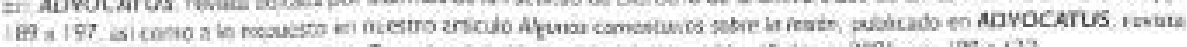

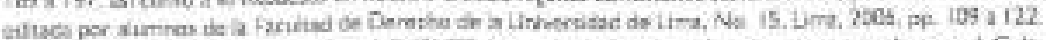

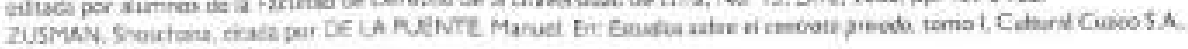

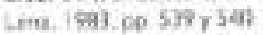


premisa que el reconocimiento de lo pactado se sustenta en la existencia (y subsistencia) de intereses dignos de tutela y protección corsiderando los intereses individiales y sociales.

\section{Yel cuarto requisito radica en que la situación de excesiva onerosidad de la prestación tebe ser eportunamente invecada}

Especial comemario merece lo dispuesto en los articulos 1445 y 1446 del Código Civit, en cuanto regulan al periodo de cadueidad para fines que la parte interasada invoque la excesiva onerosidad, porque de lo contrario se entiende que no hay afectación proplamente a sis intereses, slendo que hoportunidad a partir del cual procede el requerimierso de renilsste pressacional se sorsidera desde of momente en que finaliza el evente extracrciirario e imprevisibie, ef misme que hahria niterado el valor de la pressueión afectads. Desde dicho momento, la parte que se considere perjudicada puede reclamar por la axcosiva onerosidad, de lo contrario, su inacción equivale a una renuncia ticita y consiguiante admisión que el contrato piede ejecutarse conforme fue previsto cen ocasión de su celebración.

No debe olvidarse que estamos ante una figura ciertamente excepcional, no solo porque se resonoce que el contrato no es absolutamente inmuzable, sine porçue además permite que un tertero ajeno al vinculo restabiozca, a falta de acuerdo de las partes, el equilibro percido o, de ser el caso, declare constitutivamente la resolucién del centrato. En dicho sentida, esta figura excepeional no debe, no puede ser irwocada sin restricción temporal a guna, justificándose que se haya previsto legibativamente un plazo breve y que el mismo sea considerado como uno de caducidad, to cual conlleva una mayor rigurosidad en las reglas para su cómputo (articulo 2007 del Código Civil).

Esta exigencia temporal representa adicionalmento un mayor argumento para destacar que la excesiva cnerosidad presupone un contrato vellido y vigente, siondo que la pretensión de la parte pretencidarrente perjudicada por el evento extracrdinario o imprevisible debe invocarse opertunamente. El hecho de proseguir la ejecución del contrato, y que este se extinga por su cumplimiento total, significa, interpretando la conducta cortractual, que el deudor supuestamente periudicado no is estaba realmente.

Por último, habiendo ser̃alado anteriormente que estames ante ura figura que corresponde a un beneficio legal, solo es posible su aplicación en la mecida que así lo sstime la parte irteresada. la parte contractual alectada por la dificultad excrema, por lo que no corresponde su imocacion de oficio por autoridzd jursdiccional alguns, de igual manern come ocurre con la deneminada excepción de incumplimiento, por ejemplo.

2. Sobre la base del alcince de los requisitos expuestos, no es la sola gereración do una situación extraordinana e imprevisible (estrictamente analizada dado que se está aplicando una figura que puede derivor en uma revisión de los términas y condiciones acordados libremente en su momento, o la resolveibri) lo que va a determinar uns revisión del conterido contractual para restablocer el precendido equilibrio afectado, sino que se requiere que esa situacion extraordinaria e imprevisble sea ajena a las partes, y afecte gravemerne a uma de las prestaciones tontindola en una da eumplimiento posible pero extremadamente gravoso u onercso. Por ella, en doctrina, conforme dostaca DE LA PUENTE's, mis alla que se pueda hacer la referencia genérica a la imprevisión como anomalia contractual, lo que corresponce es imocar (por la parte interesada) la generación de una excesha orercosidad de la prestación (Que es adenás la derominación recogida en nussére Código Civil) sebce la base de la imprervisión, siendo que esa excesiva onerasidad es lo que sustenta la solicitud

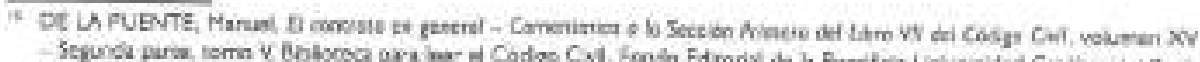

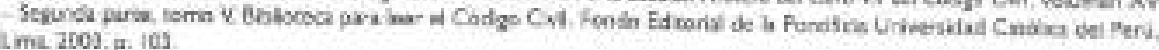


Jutisciccional de reajuste (qncrementän dose la contraprestación o reciuciéndose la prescación afoctada, y excepcianaimente, una resoiucián de cantraro), todo elo sobre la base qua al vínculo contractual esté efectivamema vigente, esto es, que la prostaciôn afectack esté pendiente de ejecucar fal igual que la contraprestaciónj, total o parciaimente.

\section{LA EXCESIVA ONEROSIDAD DE LA PRESTACION EN EL AMBITO DE LA CONTRATACION PÚBLICA}

1. Si bien en matoria de contracación pública no existe una reguación expresa sobra la flgura bajo comentario, menece destacarse que el segundo parrafo del articulo $20 \mathrm{I}$ del Feglamento de la Lay de Contrataciones y Adqutsiciones del Estado (según tenor aprobado por Decreto Supremo No. 084-2004.PCM, actualmerse vigunte) establece lo siguientu: "Elcontrato es abligetorio pora las portes y se regula por las normos de este Tituin. Los controtos de cobras se regulan, además, per el Copitulo Ill

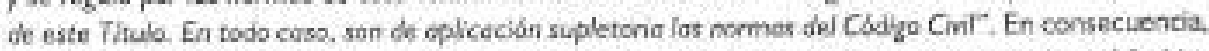
la serialada norma reglamentaria abre la posibilidad de inwocar la excesiva onarasidad en al ambiti de la contratación pública. salvo que ia requlación especifica de esta ditima no lo permita

Nuestra posición es que la excesiva onerosidad de la prescacián no es ajena, ni corçeptual ni legistativarrente, a la naturaleza de la contratación pảblica, aunque debe evaluarse su pertinencla en cada caso conereto atendiendo al cumplmiento o no de sus respectivos requisitos constitutivos.

Sobre dicho particular, hurnos seîalado precedentemente que la categorizxciän de un evento como extraordinario e imprevisible debe ser rigurosa, porque de lo contraio potria afoctarse la esonotación vinculerte de tedo contrato, lo cual pedria sigrificar un pésimo mensaje para el mercado, cesalentándosc ha contratación, hsstrumento esencial para ol intersambio. Esa intarpretación rigurasa dabo sne, en nuestra opinión, más estricta el el campo de la conaratación píblica, ya que su tratidad trasciende al inter és de las partes, más zun cuando nos encontrames ante contratos especifeos que más cue atender a nocesidades particuares del Estado (como podrian ser la provisión de materiales de escritorio), permeter ejecutar obras püblicas que fralmente benefician a la colectividad (lo qua se cenornina "interès público"), representando un mecarismo de cocperación erzro azentes privados y píblicos que permite el cumplimienco de las funciones del Estado, conforme reflece autorizada doctrina. ${ }^{\circ}$

El hecho que las concratos públicas se encuentren sometidos finalmenne a las reglas del Códgo Civil no significa, desde luego, equiparar el interés propio de la contratación privada. esarcialrnente individual, con el interés público que sustenta $u$ orienta a ła cectratación pública. lo cual legzima conceptualmento la existencia de cierta clase de estipulaciones a favor de ia Administrdeión que seriar probablemente inadmisibles en un contrate privado. Ya hemos expresado que los contratos administrativos tienen cierta finaliond singular porque buscan satisfacer un iaterés publice, en ol sentida colectivo, social, ances que eninentemente particular o privado", lo cual deciva en la pertinencia de ias denominadas "prerregativas públicas", esto es, el rógimen de faculrades singulares que cuentan las entidades públiças respecto de lo que es la interpretación.

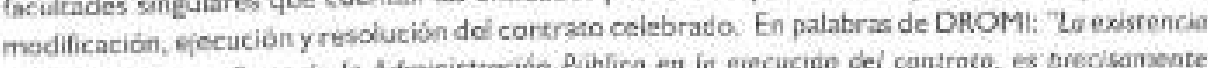

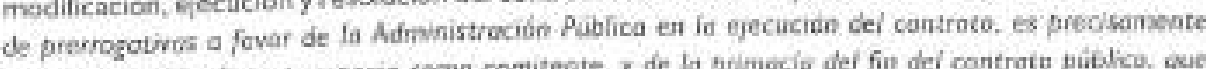
to manfestoción de su prevencio como comitente, $y$ de lo primocia del fil del controto público, que es siempre uno razón de bien comìn, a uno prestacion de incepés general, sobre lo intemción de fas

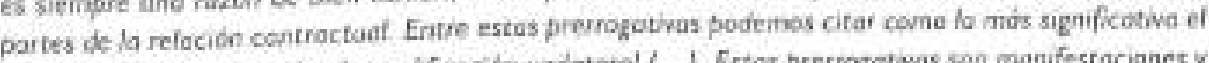

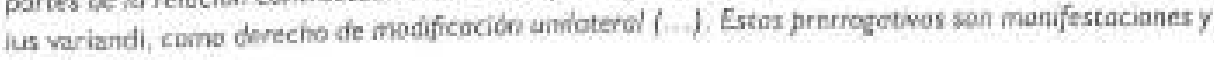

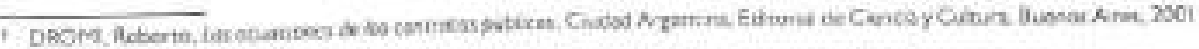

10. 25,27

DRDM Sobnisa Op Clif 27 
exlerierizocienes privotivas del poder püblico. De las mismas resuito que no hay ana igaaldad juridica sustencial entre las contratontes, entre comitente y contratista o concesioniaria, Les "cidusuís exorbitontes dei derecho común" hacen a la esencia de estos canventos, y par elia, aungue no haren sifo expresamente poctodas, están implicitomente incorporadas (... . " " *

En otras palabras, mientras que las denominadas clíusulas exorbitantes o vojatories son cuestiorables en el ambito del dereche común, de la contratación privada, porque rompen is simetria (ideal) que debe mediar entre la partes, evidenclando abuso del derecho, de manera particular trataindese de aquellos contratos qun no son suscoptibles de negocisción preva (coneratos por adhesión, por ejemplo), las mismas no son la excopoión en el ámbito administrativa, ya que por la naturaleza del objeto de la contratacón públice es consustancial que las entidades se reserven ciertas facultades, prerrogativas o privilegios que les permiten cimplir con a finalidad del contrato interés público), sientlo quo las partes saben desde un inicla que no estan en un misme plano de absoluta igualdad prepie del ímbito chil. Sobre este particular resulta concluyence lo expresado por DE LA PUENTE, ent el sentido que: "l. . ) los efectos de les controtes odrainistrotivos no san he mimar que los de los cantratos cinies. Quien concluye tin cantrato adminstrotmo no salamente osume le obligocián de no entappecer el funcionomiento del semolo pübilica, sine tombién de focilitarlo. Las cantrotes civiles suponen dos cantrutentes en ple de perfecze igualudad. El cartroto odministrotivo propiomente dicho supone, eseneialmente, das contratentes que se reconocen en pie de desigualdad. uno represento of

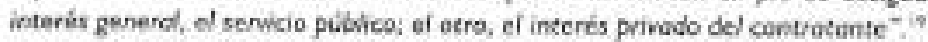

Sin embargo, en lo rolacionado a la excesiva oncrosidad de la prestación, no conccemos de dispesición legal, en el ámbito de la contratación pública, que restringa la posibilidad de su invocación por ef interesado, en particular (mas no exclusivamente) tratandoso del contratista, por lo que al no ser materia de determinada disposición exorbitante legal o corvencionsk, abe teóricamente su aplicación ye que no desnaturaliza la esencia ni la racionalidad de un contrate poblico, es mis se trata de una figura que permite mamener el equilibrio definido por las propias partes al contratar.

2. Retornando el caso del contrato de obra propuesto en un inicio, relacionado a la contratación en moneda extrarjera $\gamma$ a los consecuencias de la variación cambiaria respecto a la moneda macional, deba considerarse doe grandes premisas preliminares en ef danbito de la contratación pública: primero, que nuestra leżsaeión permite que pueda contratarse tanto en moneda racional come en moneda extranjera; y segunde, que trataindose de les contrates celebrados en moneda nacional se regula reglamertariamente el mecanismo de rea/usne (formilas polinómicas) de las respectivas valorizaciones (poges) de babra y de sis adicianales. Las normes sobre contratací́n püblica (Toxto Unice Ordenade de la Ley de Constrataciones y Adquisiciones del Estado, y su reglamento, aprobados por Decrecos Supremos Nros. 083 y 0B-4-2004-PCM, respectivamente) no hacen referencia $z$ un reajuste de las valorizaciancs de las contratos de obra celebrades en moneda extranjera, por lo que si ello no ha sido pravisto en la Bases o en ei contrato, no resiltaria procedente al reajuste en cuesción.

En el caso concreto propuesto, las respectivas Bases establecian que bo oierta debtia elaborarse en Dólares de ios Fstados Unidos de América, sienda que los respectivos progos so realizarian en dicha meneda (salwa el Impuesto General a las Venta) y de manera paralela y proporcional a la ejecucićn de la abra. Por su parte, en el correspondiente contrate se disperia expresamente que el prscio contractual no estaria sujeto a reauste alguno surante la ejecición de los trabajos, por ningin concepto.

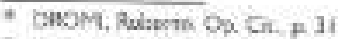

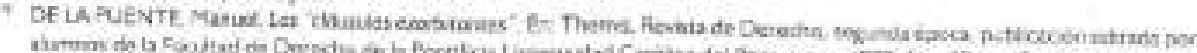

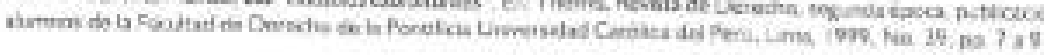


No obstante las especificas previsiones señaladas, la empreca conkrat sta demanda artitralmente el reajuate prestacional de los pagos a cargo de la entidad púbilca, bajo ol argumento que habiandose gererado un cambio radical en as circunstancias cambarias, se debe proceder al reajuste, siendo que al encontrarso en etapa de liquidación, ello debe ser considerado al aprobarse esta útrima. For su parte, sa encidad nicgn la posibilidad del resiuste, manifestando que al haberse comaramio on moneda extranjera ello significa is asunción implicita dol riesgo cambiario, siendo asicionalmante que el contrato niega expresamente la posibädad de reajuste Alguno del precio. Camesponde analizar, por lo tanto, si resilta procedente o no lo reckerado.

a) Si recurrimos, en primer lugar, a las conceptos generales apicables a la excesivos onerosidad de la prestación, debe conchuirse que nada impide aplicar, en general, dicha figura en la cantratación pública, por lo que de plano deberban descartarse los argumentos de asociar la figura en ciestión con los contratos privados. Para clo, resultan concluyentes los alcances del segundo párrafo del articulo 201 del Reglamento de la Ley de Contrataciones y Adquisiciones del Estado (Decreto Supremo No. 084-2004.PCM), los cuales complementan los aicances del articulo 1353 del Código CMil, de manera quelas disposiciores de la parte gereral del Derecho de Contratos contenidas en el sefhalado cuerpo normatimo se aplican por igual tratándose de contratos de derecho privado como de derecho püblico (en lo que no se desmaturaicen estos últimos, dosde luegoi).

Postular una separación radical entre las reglas de la contratación privada y pública es ajgo que ha quedado definitivamente desfasado.

b) No obstante lo anterior, en el case concreno, surge la cuestión si el hecho de haberse contratado en moneda extranjera y haberse dispuesto en el respectivo contrato que al precio no es susceptible de reajuste impide aplicar la figura de ia excesiva enerosidad de la prestación. Considerames que la cuestión rndica osencialmente en determinar cidies son los alcances de los pactos en cuestión o, eniocado desde otra perspectiva, si ellos impiden la aplicación de la excesiva onerasidad da la prestación. Y para ello, debemos asumir una posición critica. Nopodemos quodarnos en un inmovĭsmo de sostener, parafraseando cierto adagio juridico, que no diferenciaremos donde el pasto no diferenció, porque para desentraĩar el sentida de la ley o del acuerdo cantrsctual es fundamental identificar la premisa, el supuesto de hecho, sobre el cual se asientan sus ajcances.

\section{v. LADIFERENCIA CAMBIARIA COMO EXPRESIÓN DELAEXCESIVA ONEROSIDAD DE LA PRESTACIÓN EN EL CASO PROPUESTO}

I. Si partimos que la excesiva onerosidad de la prestación se sustenta, conforme hemos analizado, en una situacisa extraordinaria e imprevisible que desermina un grave desequilibrio prestacional sobreviniente a la celebracoón del contrato y mientras éste se mantenga en vigencia. consideramos que de manea general o abstracta, por mas que se hubiera contratato en una "moneda fuarte' como es el Doblar de los Estados Unidos do Annérica, o que se entrcie que no hay posibilidad de resuste alguno, todo elo na impide la aplicación da la figura en cuestión, por cuanto la excesiva onerosidad se funciomenta en lo que las partes no pudieron razenabiemente assimar al momento de contratar" porque se ha generado un oveme qua sobrepasa lo previsble, lo que se deriva de las condiciones normales, esto es, se evidencian riesgos extraordinarios.

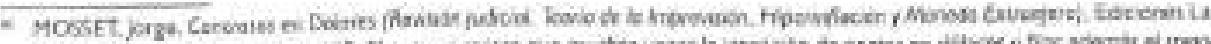

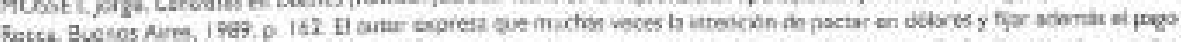

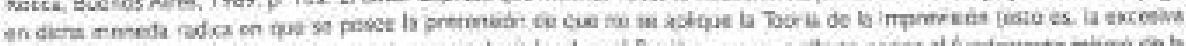

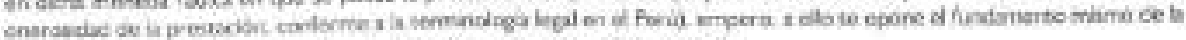

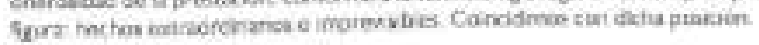


Sobre la base de dicha premisa, via interpretación debe concluirse que las aicances del pakto sobre la improcedencia de reajustes del precio expresado en moneda extramjeca debe entendersen limitado a las circurstancias comunes, usuales, tipicas is ondinarias. No se aplica la restricción contractual respecto de lo imprevisible. Ademis, sobre la base de lo sancionsdo en el zriculo $\mid 444$ del Código Civî, en aplicación supletoria, seria nulo todo pacto que pretenda desconocer el beneficio legal derivado de la pesibil dad de poder imocar la excesiva onerosidad de la prestación, siendo cue dicho pacto ne se sustercarla en primiegio alguno que, por la naturaleza de la contratación pública, le pudiese correspender a unz entidad páblics.

Por lo ranta, dado que el supuesto de hecho de la restricción contractual sabre reajustes del precio son las sianciones comines u crdinarias, de mediar situnciones excraordinarias, se requiere también de un mecarismo extraordinario, el mismo que debe cuidarse de aplicar considerando su excepcionalidad.

2. La posiblidad de una revisión contractual por desequlibrio sobreviniente es, en rip̧or, ajena a la moneda bajo la cual se contrató, porque la alteración de las circunstancias podria producirse tanto en contratos celebrados en moneda nacional como en moneda extranjera, pero resulta innegable qua h situación se presta ficilmertce; a priori, para rechazar dicha posibilidad cuandes sen comrató en moneda extravjera, de un lada. poreae podría afirmarse que se asumió implícitamance el riesgo cambisrio $y$ de otro lado, perque en el caso conereto se cuenta con una clísusula contractual cue dispone la improcedencia de reajuste del precio concertado en moneds extranjera, sin diferenciar situaciones, por toda razón o concepte.

No obstante, la aplicación efectiva de la figura bajo comencario radica finalmeate en que la diferencia cambiaria represente realmente un evento extraordinario e imprevisible, una situacín ciertamente grave, trascendente, que determire un manifiesto e inobjetable desequllbria, sin perjucicio que la respectiva reclamación debe cumplír concurrentemente con los requisitos ya enureiados. Debemos tener siempre presente que la posibilidad que un tercere ajene al vínculo intervenga respecto al contenido de la relación contracrual, fijándolo, actualizándolo, ya es de por si una sinunción atipica, de manera que la figura de à excesiva onerosidad de la prestación debe aplicarse como lo que es, una de cardicter excepoianal, que damanda suma rigurosidad en la comprobación de sus requisitos constitutivos, evitandose así que pueda invocarse sin mayores limitaciones afectando finalmerite la premisz general que los contratos son obligatorios y deben cumplinse, conforme a lo expresado ibremonto en clics.

3. Señalarnos en su oporturidad que la excesiva onarosidad de la prestación presupone cuatro requisitos constitutives concurrentes.

- Dificultad extrema.

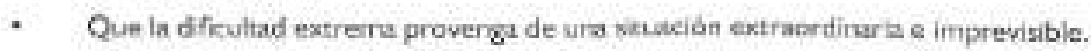

- Que la sifuación extraordinaria e imprevisible sea sobreviniente a la celebración del contrato $y$ ajona a las portes.

- Que la dificulad extrema sea aportunamente invocado por al interesado.

Ya no nos corresponde reabrir los comentarios respecto a cada uno de elios, pero sobre le base de la expreando en su oporturidad, tratándose dal caso propuesto podernos destacar lo siguierte:

a) Conforne temos marifestado, una variación del bjóo de cambio, sea por devaluación o revaluación de la moneda nacional, podria sar ecosidarado como un evento que juatifieue la aplicación de la excesiva onenosidad de la prestación en la medida, de un lado, que ullo se 
considere como una real situación extraordinarin e imprevisible $y$, de otro lado, que derive en una grave dificultad jara poder eumplir con la prestacićn afectada por ques invoca ia figura en euestidin.

Esa variación del tipo de cambio podria ser extraocdinaris cuando escapa de los märgenes usuales, normales u ordinarios, como secia una devaluación traumática. por ejemplo al cuarenta por clesto considerando ia fluctuación cambiaria en nuestro medio, parque de lo contrario estamps ante un proceso progresivo, parmanente, en donde la diferencia de cambio se convierte en un tema absolutamente ordinanio, esto es, un resgo tipico o normal, el eual corresponderá ser asumido por quien injustificadamento invoca la imprevisión. A su vez, la variación dal tipo de carobio será imprevisible cuando las partes no pudieron estimar razonablementa, atendiendo a su experiencia, que se produciria: no obstante, consideramos que el solo hecho de pactar en monedz extrariora ya sfecta de alguna manera este carácter de imprevisiblidad, porque en al fondo hay una voluntad comùn de anticiparse in cualquier problema carnbiario, sea devaluatoric o revaluatocio.

S se cumplen los dos requisitos conctrrentes procedentes, habria material ebjetiva básico para reclarnar una escesha onerosidad, sjeto al cumplimianto de los demás requisitos legains. Sin embargo, no es ad tratíndose do la reciamación a la cual se refere el caso propuesto.

En efecto, consideramos que, en el ctso conereto; no estamos ante un becho extraordinario.

Recordemos gue hemos postulado que la calificación de lo que es extraordimario e imprevisible depende de las circurstantias, de cadz situación en particular En ese orden de ideas, cabu preguntarse si estamos realmente anse una diferencia cambiara traumática. atipica, incempertiva, extraordinaria. Nada de eso, porque se ha estado ante un proceso progensivo, mensurable, predeoble. Las cifras son objetivas. El Dólar de los Estados Unidos de América, tomando las cifras expleestas por la contratista en su demandz, pasó en menos de dos años de 5/.3.472 (a la fechn del primer anticipo) a S/. 3.226 (a la fecha de la vigésino primera valorizzción, Utima), e inclusive puede destacarse que paso finalmente a S/, 3:192 (liquidación). Estamas nefiriéndonos a una difarencia de S/. 0.146 ;o, en el peor de los asos, de S; . 0.280) por cada dólar americano, respecto a la progresión de pagos de las valoriaciones. Dado que la terdensia de raduccib́n dol sipo do cambio era previa fortes inclisive de la celcbresción del contrato y primer pago), consideramos que no estamos ante una situación extraordiraria y menos aún de caracter imprevisible. Una revaluación que no llega ni al dicz por ciente en el periodo ruclamado (abo menes de dos anos) no es, ni puede ser considerada seriamente en nuestro medio como un evento extraortinario que jusctique una rewsión contractual, màs aun cuando todos los dias hay altibajos cambiarios con una tendencla mensurabia.

Da manera adiciond, sampoco consideramos que, en el caso propuesto, estemos ante un hecho realmente imprevisible:

Sobre este particular resulta conveniente netomar lo expresado por Messineo ciando sestiene

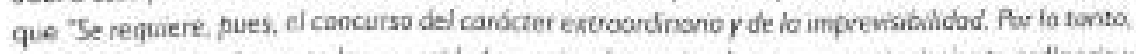
es irrelevante no spiamente ka anerosided exceswa deteminado por un ocentecimiento ardinario y prenisile, sino tombien la determinodo por un acontecimeato onornal pero ponvisible. Y eso tanto más si en ef momento de la canclusidin def centroto se hobian perfllode circuestancies que, can 
certeza a con extrema prababilided, hubiesen conducido a bo olteraciër de ia situociỏn econdmicc tamado en cansideracibo par las partes ${ }^{*}$ il

$Y$ es que, desde el mornento en que er las Bases del proceso de sclección seguido sa tepresó que la aferta debá elatararse en Dólares de los Estados Unidos de Améries es obvio que se estaba representanda la posiblidad do ina fuctuación cambiaria, la cual porila bereficlas o perjudicar a la empresa contratista. Debe tenerse presente, ademís, que la contratista se sometió volumaria y libremente, acuptíndolas, a las disposiciones de las Bases, siendo que en elias se expresaba foroforma contractua) que no habria lugar a reajuste alguno, conforme se formalizo posteriomente al celebrarse el contrato.

b) Pero no solo se trata de elle, sine que adernás te debe analizar la conducta de ta parte interesada que imoca a beneficie legal bajo comentario, de manera consrata er cuanto al hecho que la contratista (pretendidamente perjudicada por la excesiva onenosidad) ao suspendió (o, al menos, planted la posibilidad de susponsión) la ejecución contractual n interpuso inmedistamente, dentro del breve plazo de caducidad que establece b ley farticulos 1445 y 1446 del Código Chili, la acción para obtener el reconocimiento jurisdiccioral del supuesto prableme, sino que prosiguió con la ejecución normal del contrato, siendo que recién reciama cuando este ya se ejecutó, lo cual significa inchusive que habria un comportarvento de mala fe, ya que en la actualichad se exige (extemporáneamente) un reajusce sin que la entidad (contraparte contrsctua) tenga a posibilidad de resolver el contrato, to cusil sigaifica desconoser el derecha potestative que le asiste legaimente por la propia naturaleza de la excesive onerosidad.

Conforme hemos expucsto, ka excesiva onerosidad, que legitima una revisión contractual, demanda que el vinculo esté vigence, y es que ia generación de un riesgo extraordinario e inpreviable de manera sobreviriente a su celebratiōn afocta su ejecuciör, de alli que fl pratandide alectado requiera jurisdiccionalmente el ajuste prestacional, respocto de lo cual al emplazade puede optar por la resclución, ya que la prestación finalmente le puede resultar inútil: pérdida del interés.

En el caso propuesto, que estimamos que resulia muy interesante para fines ditäcticos, no se cumpla cen dicho elemental roquisito, lo cual deriva en dos comentarios: Primero, que aún en el supuesto negado que se hubiese generado un evento extracordinario e imprevisible, elb no habria afectado realmente a la contratista para proseguir con la ejecución contrastual, acredsándose que no habia excrama dificultad que justifique una revisión de le acordadio hicialments. Segundo, de otro lado, que al proseguirse cen la ejecución y demanctar el ziuste (incremente) ex post, concluide el contrato, finalizada la ejecución, se ostầ indirectamente afectando los legítimos derechos de la contraparte (le entidad), ya que de acuurdo a ley se puade uptar, frente a la protansión de reajuste prestacional, por la resolsición contracrual. Las términos en que se piantea fa demanda evidencian, por consiguiente, una conducta contraria a la buena fe convectual.

Desde el preciso momento en que la contratista terno "conciencia" de la pretendiela volaclídad dul tê de cambjo (aunque reiteramos que, en nuestra opinión, ello no es ni excraordinario ni imprevis ble, ni genera efectos graves), con su supuesto impacto negativo ensus uxpectativas negociales, su omialón de imerponar oportumamensa la acción coerespondiente (en sede abitral conforme al cecterato de obra) derivó inexurablemento an que el contrato en cuestión siguiera ejecutándose normalmente icomo si no se hubiese presentado dificultad extrerra respecto a la prestación comprometida), conforme $z$ lo

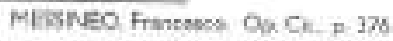


previsto; resulmria alasurdo contradecir hoy en dia dicha actuación reclarrando respecto de hechos corsurnados par conducta concluyente de la propin contratista ${ }^{27}$, ya que el contrapeso de ura reclaración de reajuste es que la contraparte pueda solicitar la resolución del contrato al haber perdido intanés an el negocio en atención a la posibie modificación de sus términos y condiciones.

La contratista esper 6 inexplicablamente, violentando la buesa fe, la ejecudion toxal del contrato e ingresar a su etape de liquidación para recién imocar la pretencída excesiva onerositad, haciende con ela inviable, nula, la posibildad que la entidad pudiera optar por la resolución, "obligsidola" de dicha manera a que asuma los supuestos mayores costos por la diferencia cambiaria. Ess mariobra no puede dejarse de destacar ponque no solo resila que no hubo excesina onerosidad ya que la prestación de la contratista se ejecutó conforme a lo previsto. sino porque además pone en evidencia que so ha insentado manipular la figura para obligar a la enticiad a que terga que asumir los pretendidos mayores sobrecostes, ya que al haberse ojectcado el contrato, no hay posibilidad de poder optar por la resolución.

c) Por último, Intimamente relaciónado a lo anterior, hahiéndose admitido que la invocación do la excesiva oneresidad de la prestación presupene una relación contractual vilida y vigente, resulta siendo concepcualmente inadmisible que se solicite la revisión prestacional cuando el contrato ya fereció. En efecto, en el caso propuesto, las parnos se halan en etroa de liquidación de contrato, esto es, ya vencí́ el plazo de vigencia contractual, por lo que no habiendo preataciones por ejecucar, carnce de seritido rochamar ajustes en su vaior:

Evte solo hecho ya es determinsnta, concluyenite, en nuestra opinión pare determinar la improcedencia de lo demardado por la empresa contratista.

\section{CONCLUSIONES}

La excesha onercsidad de la prestacián se sustama, fn nuestra opinón, sobre la base de la exigancia de buora fe en la ejecución misma del contraso, principio esencial on materia de contratación y que atravesa el régimen general previsto en nuestro Código Civil, aunģue es obvio que una regulación particular y desallada sicmpra es más comveriente. Esa buena fo debe ser conaiderada como el deber de actuar dligerte, oficientemente según las exigencias o estándaros dal marcado, te manera que sobre dicha base sa determine si eran razonsbles o no las provisiones adoptadas por ls partes respecto a lo que pueda considerarse como una alteración de las circunstancias. Para dikho efocto, rasulta útil refé imos a la mensura económica de los nesgos para lines de la contratación.

La excesiva onerosidad es una figura excepcional, porque pone en entredicho el cardcter estnctamante vinculante de las scuerdos contractuales adoptades en su oporturidad; en consecivencia. debe aplicarse restrictivamente. evitindose desalentar la contratación, instrumento osencial para un intercambio seguro y eficierie, pero no par ella menos justo Desdo esa perspectiva, la rigurosa weriflcación de sus requisitos constiturjvos depende del buen criterio jurisdiccional, de la visión qué se posea respecto a la funcionalidad de los contratos.

Estimames que no existe fundarnento legal ni conceptual para excluit, del ambito de in contracación pública, por mas que ésta posea un régimen legal privativo en el cual puedar justificarse

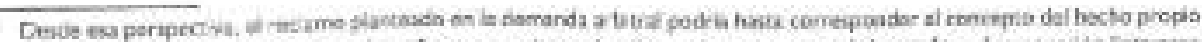

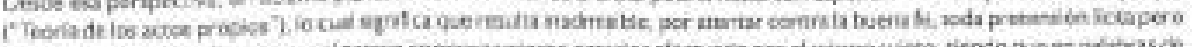

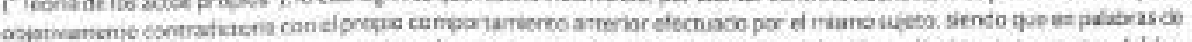

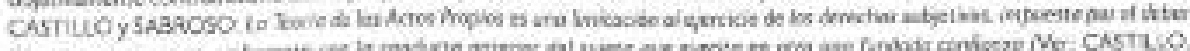

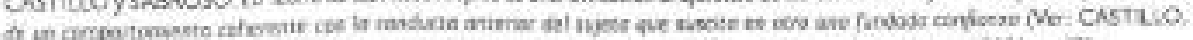

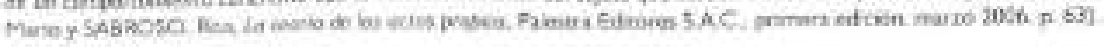


denerminadas ese/pulaciones esorbitantes, la aplicsoón de la fiqura legal bajo comantario, y es que la variación de las circunstancias puede presentarsa an cualquier esconario, por lo que resultaria prejuiciese considerar cesa distinca.

Atendiendo a lo expuesta, en el caso red propuesto, cansideramos cue, desde distintas perspectivas, no resulta procodente la reclarmaciên de h empresa contratista por pretendida excesiva onerosicad de la prestación, pero no on razón que ol contrato no permita (de manera general) al reajuste por haberse pactsdo en moneda extranjera, ni porque pueda considerarse que la figura en cuestión es prepia o exclusiva de la contratación privada, sino porque no so cumple con las requisitos corrstitutivos de dicha figurz, sendo mis bien que el comportamiento de la contratista denota unz vountad de aprovechamiento inciebido, resultando sintomático que demande el reajuste prestacional cuando el cantrato ya fue ejecutado, la cual representa una infracción al principio de buena fe contractial, ya que se le nega contextualmenea a la entidad el derecho de poder invocar la resolueión del contrato. 